\title{
Avaliação da qualidade do composto proveniente da compostagem da fração orgânica dos resíduos sólidos domiciliares
}

\author{
Compost quality assessment from organic household waste composting
}

\begin{abstract}
Luciana Miyoko Massukado* Engenheira Civil. MSc. em Engenharia Urbana (UFSCar), Doutora em Ciências da Engenharia Ambiental - EESC/USP. Professora do Instituto Federal de Educação, Ciência e Tecnologia de Brasília-
\end{abstract}

Campus Planaltina

Valdir Schalch

Engenheiro Químico. Doutor em Hidráulica e Saneamento - EESC/ USP. Professor do Departamento de Hidráulica e Saneamento da

Escola de Engenharia de São Carlos (EESC/USP)

(*) Endereço: Rodovia DF-128, km 21, Zona Rural, Planaltina, DF CEP 70380-900Tel (61)3905-5407e-mail: luciana.massukado@ifb.

Recebido: 20/01/2010 Aceito:29/03/2010

\section{RESUMO}

O objetivo da pesquisa foi avaliar a qualidade do composto proveniente da compostagem da fração orgânica dos resíduos sólidos domiciliares, que foi previamente separada na origem, pelos moradores, no momento do descarte. A qualidade do composto foi analisada a partir de parâmetros físicos, químicos e microbiológicos. Os resultados indicaram que o composto atendeu à maioria dos limites estabelecidos pela legislação brasileira, principalmente, com relação ao teor de metais pesados $(\mathrm{Cd}<0.5 ; \mathrm{Pb}=1.3 ; \mathrm{Cr}=17.4 ; \mathrm{As}<0.5 ; \mathrm{Hg}<0.5 ; \mathrm{Se}<0.5$ e Ni=0.8 $\mathrm{em} \mathrm{mg} / \mathrm{kg}$ ) e presença de organismos patogênicos. No entanto, quando esse composto foi submetido ao ensaio ecotoxicológico - teste agudo em minhocas da espécie Eisenia andrei - constatou-se toxicidade do mesmo, com taxas de mortalidade significativas $(\mathrm{P}<0.05)$ a partir da concentração de $16 \%$ de composto em solo artificial tropical (TAS). Apesar do ensaio ecotoxicológico não identificar o que está causando a toxicidade ele desempenha papel de indicador de possível contaminação, tanto ambiental quanto para a saúde humana. A partir da avaliação integrada entre os diversos parâmetros de qualidade do composto, infere-se que a alta condutividade elétrica do composto (CE $=7,48 \mathrm{mS} / \mathrm{cm}$ ) pode ter contribuído pela toxicidade do composto, na sobrevivência das minhocas.

PALAVRAS-CHAVE: compostagem; qualidade do composto; ensaio ecotoxicológico, resíduos sólidos domiciliares.

\section{ABSTRACT}

The research aimed to evaluate compost quality from organic household waste composting, which was separated, by householders, before discarded them. The compost quality was analyzed by physical, chemical and microbiological parameters. The results showed that compost attend the most limits established by Brazilian legislation, e.g., heavy metals concentrations $(\mathrm{Cd}<0.5 ; \mathrm{Pb}=1.3 ; \mathrm{Cr}=17.4 ; \mathrm{As}<0.5 ; \mathrm{Hg}<$ $0.5 ; \mathrm{Se}<0.5 \mathrm{e} \mathrm{Ni}=0.8 \mathrm{in} \mathrm{mg} / \mathrm{kg}$ ) and presence of pathogenical organism.
However, the ecotoxicological essay - acute test with Eisenia Andrei earthworm - indicated toxicity in the compost, with significance mortality rate $(\mathrm{P}<0.05)$ concentration when above $16 \%$ of compost in the tropical artificial soil. Although ecotoxicological essays do not identify what is the cause of toxicity, it can be seen as an indicator of some contamination. Considering an integrated evaluation of compost quality parameters, one's can infer that the high electric conductivity $(\mathrm{CE}=7,48 \mathrm{mS} / \mathrm{cm})$ could be contributed for the compost toxicity to earthworm survival.

KEYWORDS: composting; compost quality; ecotoxicological essay, household waste.

\section{INTRODUÇÃO}

A dificuldade para se encontrar locais ambientalmente adequados e economicamente viáveis para a disposição dos resíduos sólidos demanda dos municípios a adoção de estratégias que prolonguem a vida útil dos aterros sanitários. Isso significa implantar programas que tenham como objetivo desviar ao máximo a quantidade de resíduos aterrada, tanto os recicláveis quanto os compostáveis.No Brasil, os resíduos recicláveis representam, em média, 20 a $30 \%$, em peso, do total de resíduos encaminhados para um aterro sanitário. Ao contrário do grande volume ocupado pelos recicláveis, os resíduos orgânicos têm como principal característica a rápida degradação e, representam, em peso, cerca de 50 a $60 \%$ dos resíduos encaminhados para um aterro. O problema é que o ambiente anaeróbio, no qual ocorre a degradação dos resíduos orgânicos, permite a geração de produtos indesejáveis, tais como o chorume e o gás metano, ambos com elevado potencial de contaminação. Sob esse ponto de vista é interessante que esses resíduos sejam coletados e tratados em locais adequados, assim como já ocorre com os recicláveis. Evitar a disposição da fração orgânica nos aterros sanitários significa aumentar a sua vida útil, ou então que para um mesmo período sejam construídos aterros menores. Do ponto de vista econômico, diminuem-se os gastos com transporte (caso a compostagem seja realizada em local mais próximo aos geradores), disposição final e tratamento do chorume.Uma das alternativas viáveis para desviar a fração orgânica dos locais de disposição é a compostagem que pode reduzir mais de $60 \%$ o volume de resíduos orgânicos, produzindo ao final do processo, um material estável que pode ser utilizado como condicionador de solos ou até mesmo atuar como um fertilizante. Resumidamente a compostagem pode ser definida como um processo controlado de decomposição aeróbia e exotérmica da substância orgânica biodegradável, por meio da ação de microrganismos autóctones, com liberação de gás carbônico e vapor de água, produzindo, ao final, um produto estável e rico em matéria orgânica (DE BERTOLDI et al., 1983; SENESI, 1989; ABNT, 1996; KIEHL, 2004). No Brasil, existem poucas plantas de compostagem em funcionamento, sendo a maioria caracterizada por instalações do tipo centralizadas e mecanizadas que processam os resíduos oriundos da coleta misturada. Como os resíduos chegam misturados, tem-se um produto final de baixa qualidade e eficiência do ponto de vista agronômico (presença de materiais indesejáveis e metais pesados). Considerando o cenário predominante da compostagem no Brasil, a proposta do trabalho foi investigar se a compostagem dos resíduos orgânicos, previamente separados na origem contribui para melhorar a qualidade do composto. Para tanto os resultados foram comparados aos parâmetros de qualidade estabelecidos pela legislação brasileira. 


\section{Compostagem sob a ótica da descentralização}

Muitas experiências de compostagem nos países em desenvolvimento remetem às grandes plantas centralizadas e mecanizadas que, por utilizarem tecnologias inapropriadas ou não disporem de mercado para escoamento do composto ou mesmo pela escassez de recursos para operação e manutenção, se vêem obrigadas a encerrar sua atividade (ENAYETULLAH e MAQSOOD, 2001; ROTHENBERGER et $a l, 2006)$.Dessa forma, a descentralização pode ser uma alternativa para o gerenciamento dos resíduos orgânicos, uma vez que poderia proporcionar redução nos custos de transporte, aumento na taxa de compostagem além de usar tecnologias de baixo custo baseadas principalmente na disponibilidade de mão-de-obra (ENAYETULLAH e MAQSOOD, 2001; BADE et al., 2005; ACR, 2005).Um dos princípios da compostagem descentralizada é tratar a fração orgânica o mais próximo possível do local onde os resíduos foram gerados, como por exemplo, no próprio domicílio, em áreas institucionais de um bairro, de uma indústria e de escolas.Quando a compostagem descentralizada extrapolar a esfera domiciliar pode-se pensar na implantação de modelos coletivos de compostagem, os quais demandarão espaço físico maior. Nesse caso, o dimensionamento do local não deve levar em consideração somente a quantidade de resíduos a tratar, mas também os tipos de resíduos, o que existe no entorno, a direção do vento, o mercado potencial, o raio de ação e as aplicações do composto.

Tabela 01: Relação das leis brasileiras relacionadas à qualidade do composto orgânico

\begin{tabular}{|c|c|}
\hline $\begin{array}{r}\text { Lei, Decreto ou } \\
\text { Instrução Normativa }\end{array}$ & Descrição \\
\hline Lei Federal n 6894/1980 & $\begin{array}{l}\text { Inspeção, fiscalização da produção e comercialização de } \\
\text { fertilizante }\end{array}$ \\
\hline Decreto Federal no 4954/2004 & Regulamenta a Lei $n^{\circ} 6894 / 1980$ \\
\hline $\begin{array}{l}\text { Instrução Normativa } n^{\circ} \\
23 / 2005\end{array}$ & $\begin{array}{l}\text { Definição e } \mathrm{n} \text { ormas sobre especificações e as garantias dos } \\
\text { fertilizantes }\end{array}$ \\
\hline $\begin{array}{l}\text { Instrução Normativa } \\
\mathrm{n}^{\circ} 27 / 2006\end{array}$ & $\begin{array}{l}\text { Estabelece concentrações máximas admitidas para } \\
\text { contaminantes }\end{array}$ \\
\hline $\begin{array}{l}\text { Instrução Normativa } n^{\circ} \\
24 / 2007\end{array}$ & Reconhece os métodos analíticos \\
\hline $\begin{array}{l}\text { Instrução Normativa } n^{\circ} \\
28 / 2007\end{array}$ & Aprova métodos analíticos para fertilizantes \\
\hline
\end{tabular}

A Instrução Normativa IN n 23 (MAPA, 2005) denominou o composto de lixo como "fertilizante orgânico composto, obtido pela separação da parte orgânica dos resíduos sólidos domiciliares e sua compostagem, resultando em produto de utilização segura na agricultura e atendendo aos limites estabelecidos para contaminantes". Segundo a classificação dessa Instrução Normativa, o composto de lixo pertence à Classe "C", ou seja, aquele que, em sua produção, utiliza qualquer quantidade de matéria-prima oriunda do lixo domiciliar, resultando em produto de utilização segura na agricultura. Para esta classificação são determinados limites e tolerâncias quanto a sua qualidade. Esses limites são apresentados na Tabela 02 .

\begin{tabular}{cc} 
Tabela 02: Especificações dos fertilizantes mistos e compostos \\
\hline Garantia & \multicolumn{1}{c}{ Fertilizante orgânico composto Classe } \\
& "C" \\
\hline Umidade & Máximo de $50 \%$ \\
$\mathrm{~N}$ total & Mínimo de 1 \\
$*$ Carbono orgânico & Mínimo 15 \\
$\mathrm{pH}$ & Mínimo de 6,5 \\
$\mathrm{Relação} \mathrm{C/N}$ & Máximo 18 \\
*Relação CTC/C & Mínimo 20 \\
\hline *Valores expressos em base seca, umidade determinada a $65^{\circ} \mathrm{C}$
\end{tabular}

Fonte: IN no 23 (MAPA, 2005).

\section{Qualidade do composto}

Devido ao fato da compostagem ser um processo de decomposição aeróbia, o monitoramento e controle dos fatores físicos, físico-químicos e biológicos se fazem necessários para a obtenção de um composto que apresente qualidade suficiente para atuar como condicionador do solo ou até como fertilizante orgânico.Avaliações realizadas do composto mostram que as características de qualidade são essencialmente herdadas dos resíduos que deram origem ao processo, mesmo sofrendo influência dos parâmetros como umidade, tamanho das partículas, concentração de N, pH, e condutividade (SAVAGE, 1996; MERILLOT, 1996; OLIVEIRA, 2000; RODRIGUES, 2004). Ressaltase que o grau de qualidade do composto está relacionado ao seu uso. A condutividade elétrica é um parâmetro importante para verificar o grau de qualidade do composto, pois serve como indicativo dos níveis de fitotoxicidade. Segundo alguns autores (KIEHL, 1998; AYUSO et al., 1996 e OLIVEIRA, 2001) elevados valores de condutividade elétrica e a alta concentração de ácidos orgânicos inibem a germinação de sementes. Na legislação brasileira é comum encontrar limites máximos e mínimos para alguns parâmetros $(\mathrm{pH}$, relação $\mathrm{C} / \mathrm{N}$, umidade, metais pesados, ovos viáveis de helmintos, salmonella ssp, nitrogênio total, carbono orgânico e capacidade de troca de cátions). Por outro lado, não se encontram referências com relação aos valores mínimos ou máximos de condutividade elétrica; de sais solúveis; da taxa máxima recomendada para aplicação do composto no solo; da temperatura e períodos mínimos que uma leira deve alcançar. Ademais, a legislação brasileira também não considera os efeitos sinérgicos dos metais pesados no solo e das interferências da aplicação do composto orgânico sobre a fauna presente no solo. A Tabela 01, a seguir, apresenta as principais leis e instruções normativas, no âmbito federal, referentes ao composto orgânico.

Em 2006, foi publicada a Instrução Normativa n ${ }^{\circ} 27$ (MAPA, 2006), que dispõe sobre os fertilizantes, corretivos, inoculantes e biofertilizantes. Para que esses possam ser produzidos, importados ou comercializados, deverão atender aos limites estabelecidos na referida instrução normativa no que se refere às concentrações máximas admitidas para fitotóxicos, patogênicos ao homem, animais e plantas, metais pesados tóxicos, pragas e ervas daninhas. A Tabela 03 apresenta os limites máximos de contaminantes determinados por essa instrução normativa.

Tabela 03: Limites máximos de contaminantes admitidos em fertilizantes orgânicos

\begin{tabular}{|c|c|}
\hline Contaminante & Valor máximo admitido \\
\hline Arsênio $(\mathrm{mg} / \mathrm{kg})$ & 20,00 \\
\hline Cádmio (mg/kg) & 3,00 \\
\hline Chumbo (mg/kg) & 150,00 \\
\hline Cromo $(\mathrm{mg} / \mathrm{kg})$ & 200,00 \\
\hline Mercúrio $(\mathrm{mg} / \mathrm{kg})$ & 1,00 \\
\hline Níquel $(\mathrm{mg} / \mathrm{kg})$ & 70,00 \\
\hline Selênio $(\mathrm{mg} / \mathrm{kg})$ & 80,00 \\
\hline $\begin{array}{l}\text { Coliformes termotolerantes - número mais } \\
\text { provável por grama de matéria seca (NMP/g } \\
\text { de MS) }\end{array}$ & $1.000,00$ \\
\hline $\begin{array}{l}\text { Ovos viáveis de helmin tos - número por } \\
\text { quatro gramas de sólidos totais }\left(\mathrm{n}^{\circ} \mathrm{em} 4 \mathrm{~g}\right. \\
\text { de ST) }\end{array}$ & 1,00 \\
\hline Salmonella SSP & $\begin{array}{l}\text { Ausência em } 10 \mathrm{~g} \text { de } \\
\text { matéria seca }\end{array}$ \\
\hline
\end{tabular}

Fonte: $\mathrm{IN} \mathrm{n}^{\circ} 27$ (MAPA, 2006)

$\mathrm{Cab}$

perr

artic

Ens

\section{Os}

recc

mel 
Cabe mencionar que ao valor do limite máximo admitido é estabelecida uma variação de $30 \%$, o que pode tornar o uso do composto muito permissivo. No entanto, essa instrução normativa estabelece, em seu artigo $5^{\circ}$, a obrigatoriedade da revisão desses em até 4 (quatro) anos a partir da data de publicação da mesma.

\section{Ensaios ecotoxicológicos}

Os ensaios ecotoxicológicos, com diferentes espécies, têm sido recomendados como uma ferramenta adicional na avaliação da qualidade do composto de lixo, contribuindo, dessa forma, para melhorar as exigências quanto à utilização agrícola desse produto (ALVARENGA et al., 2007; MOREIRA et al., 2008). Esses testes são empregados para avaliar os efeitos adversos de substâncias químicas sobre a biota terrestre e aquática (RÖMBKE \& KNACKER, 2003; GARCIA, 2004; EC, 2004), possibilitando avaliar os impactos dos poluentes para organismos do solo e dos corpos receptores. Tratando-se de composto de lixo, considera-se mais pertinente investigar o risco ambiental utilizando os métodos existentes para os ecossistemas terrestres.Com relação ao organismo-teste para ser utilizado nos ensaios de toxicidade as normas (OECD, 1984; EC, 2004) têm recomendado as espécies Eisenia foetida (Savigny, 1826) ou Eisenia andrei (Bouché, 1972), pois elas apresentam um ciclo de vida curto com juvenis saindo dos casulos após 3 a 4 semanas, atingindo a maturidade em 7 a 8 semanas e produzindo de 2 a 5 casulos por semana (OECD, 1984; GARCIA, 2004). Essas espécies são comercialmente conhecidas como minhoca da califórnia, minhoca vermelha ou minhoca para compostagem.

\section{METODOLOGIA}

A área de atuação do projeto foi a Unidade Descentralizada de Compostagem (UDC), conhecida como Pátio de Compostagem, implantada em 2005. O acompanhamento da operação da UDC ocorreu durante o período entre março de 2006 e março de 2008, sendo realizadas coletas todas as segundas, quartas e sextas-feiras. No primeiro ano, o acompanhamento teve como objetivo padronizar os procedimentos operacionais do processo, como tamanho das leiras, freqüência de revolvimento e rega. Em 2006, o material compostável era coletado em domicílios localizados no mesmo bairro do pátio. Os domicílios que aderiram ao projeto recebiam, semanalmente, sacolas específicas para depositarem os resíduos orgânicos. A partir de 2007, houve também a contribuição dos resíduos compostáveis da merenda da escola. Para operacionalizar o pátio havia um operador contratado para realizar o serviço. Durante o período da pesquisa, 29 toneladas de resíduos orgânicos foram coletadas, 56 leiras foram montadas e 5 toneladas de composto foram produzidos.

O pátio possui $45 \mathrm{~m}^{2}$ de área coberta e 55 $\mathrm{m}^{2}$ de área a céu aberto com capacidade para tratar até $4 \mathrm{t} /$ mês de resíduos. O custo para implantação da parte coberta do pátio ficou em torno de R \$ 10 mil. A Figura 01 apresenta o local onde a compostagem da fração orgânica dos resíduos sólidos domiciliares foi desenvolvida.

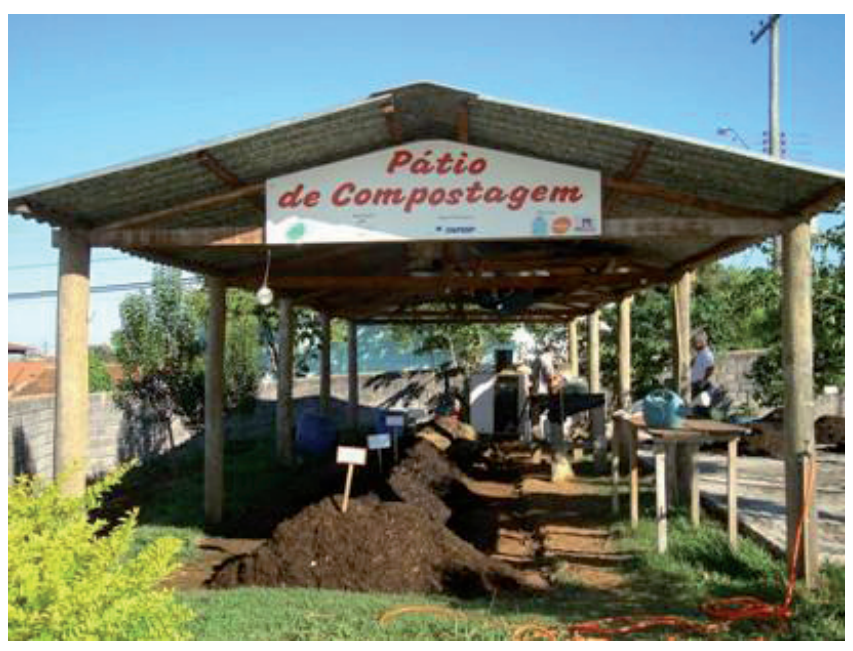

Figura 01: Escola Estadual Bento da Silva César (São Carlos/SP) - Local onde a compostagem foi desenvolvida

O método de compostagem empregado foi o de leiras revolvidas dispostas em local protegido das intempéries e submetidas a revolvimento manual a cada dois dias. As leiras apresentavam volume médio de $1200 \mathrm{~L}$ e massa entre 500 a $600 \mathrm{Kg}$, sendo cobertas com uma camada de capim ou folhas secas e tela tipo sombrite para evitar que as folhas se espalhassem e que animais (pombas, cachorros) viessem remexer a leira. . A caracterização inicial da mistura não foi realizada devido à dificuldade em se obter uma amostra representativa da leira, uma vez que os resíduos sólidos domiciliares são bastante heterogêneos e possuem um alto valor de umidade (acima de 60\%). Tentativas foram feitas para triturar a mistura inicial em equipamentos específicos, triturador de resíduos domésticos e moinhos de facas, porém as duas tentativas falharam em virtude dos resíduos se aglutinarem e, portanto, bloquear a rotação das facas.Assim, para a pesquisa somente o composto maturado foi analisado. A Tabela 04 apresenta esses parâmetros e a metodologia empregada.

Tabela 04: Relação dos parâmetros analisados, local e metodologia utilizada

\begin{tabular}{|c|c|c|}
\hline Parâmetros & Unidade & Metodologia \\
\hline Umidade & $\%$ & $\begin{array}{l}\text { EMBRAPA (1997); Monteiro; Frighetto } \\
(2000)\end{array}$ \\
\hline Granulometria & ---- & EMBRAPA \\
\hline Densidade & $\mathrm{g} / \mathrm{cm} 3$ & \\
\hline $\mathrm{pH}$ & ---- & EPA (1994) e Monteiro; Frighetto (2000) \\
\hline СTC & $\mathrm{Cmolc} / \mathrm{Kg}$ & Rodella e Alcarde (1994) \\
\hline $\begin{array}{l}\text { Capacidade de retenção de } \\
\text { água }\end{array}$ & $\%$ & Monteiro; Frighetto (2000) \\
\hline Carbono Orgânico & $\mathrm{g} / \mathrm{Kg}$ & Kiehl (1985) \\
\hline Nitrogênio Total & $\mathrm{g} / \mathrm{Kg}$ & $\begin{array}{l}\text { Oliveira et al . (2000), Nogueira e Souza } \\
(2005)\end{array}$ \\
\hline Matéria Orgânica & & Kiehl (1985) \\
\hline Relação C/N & ---- & Kiehl (1985) \\
\hline Macro e micronutrientes & $\mathrm{g} / \mathrm{Kg}$ & $\begin{array}{l}\text { Oliveira et al . (2000), Nogueira e Souza } \\
(2005)\end{array}$ \\
\hline Metais pesados & $\mathrm{mg} / \mathrm{Kg}$ & EPA (1995) SW -846, método 3051 \\
\hline Coliformes totais & $\mathrm{NMP} / 100 \mathrm{~mL}$ & APHA (1998) \\
\hline Coliformes fecais & $\mathrm{NMP} / 100 \mathrm{~mL}$ & APHA (1998) \\
\hline Ovos viáveis de helmintos & --- & APHA (1998) \\
\hline Salmonela & $\mathrm{NMP} / 100 \mathrm{~mL}$ & APHA (1998) \\
\hline
\end{tabular}


O teste de toxicidade aguda foi realizado para determinar a Concentração Letal Média (CL50) da substância-teste (composto orgânico) para uma população de Eisenia andrei. Para tanto, foi utilizado o TAS (solo artificial tropical) para diluir a substância-teste (GARCIA, 2004).

A composição, em peso, do TAS foi de $70 \%$ de areia, $20 \%$ de caulim e $10 \%$ de fibra de coco. O teste foi baseado nas normas OECD 207 (OECD, 1984), ISO 11262-1 (ISO, 1993) e NBR 15537 (ABNT, 2007). Os ensaios foram conduzidos em potes plásticos redondos contendo, cada um, aproximadamente $500 \mathrm{~g}$ de substrato seco (diluições do composto no TAS). Foram realizados 9 (nove) tratamentos para a substância-teste, ou seja, 9 (nove) diluições do composto no solo artificial: $100 \%, 75 \%, 64 \%, 50 \%, 32 \%, 25 \%, 16 \%, 10 \%$ e $8 \%$. Também foi montado um recipiente contendo somente o TAS, que foi utilizado como controle. Os potes plásticos foram identificados com o tratamento e o número da réplica $(1,2$ ou 3$)$ e suas tampas perfuradas de modo a permitir a oxigenação do meio. O preparo das misturas foi realizado manipulando-se o tratamento menos contaminado (100\% de TAS) até o mais contaminado ( $100 \%$ de substância-teste).

A mistura de TAS, substância-teste e água destilada foi realizada, manualmente, em uma bandeja plástica e depois transferida para os potes de ensaio.Após aclimatação no TAS por um período de no mínimo 24 horas e antes de serem colocadas nos potes correspondentes a cada tratamento, as minhocas foram lavadas em água destilada e seca em papel de filtro. As minhocas utilizadas no ensaio apresentavam clitelo desenvolvido e pesavam entre 200 e $400 \mathrm{mg}$. Em cada recipiente foram adicionadas 10 minhocas. Os recipientes foram distribuídos aleatoriamente sobre a bancada do laboratório (Figura 02), na qual permaneceram por 14 dias, sob temperatura de $25 \pm 2^{\circ} \mathrm{C}$, em regime de 12 horas de luz e 12 horas de escuro.

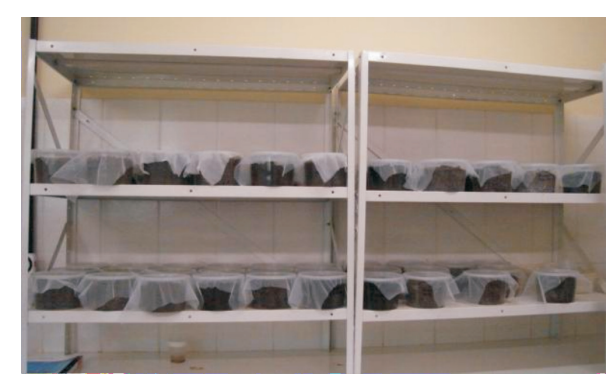

Figura 02: Distribuição aleatória dos recipientes na bancada do laboratório de ecotoxicologia.

Para os testes de toxicidade aguda, foram obtidos gráficos com os valores de mortalidade/concentração, estimando-se a concentração letal média (CL50), com limites de confiança de 95\%, pelo método Trimmed-Spearman-Kärber.

\section{RESULTADOS}

\section{Qualidade do composto}

Com relação à temperatura das leiras, verificou-se que a maioria alcançou valores de $70^{\circ} \mathrm{C}$ ou manteve-se na fase termófila (entre 45 a $65^{\circ} \mathrm{C}$ ) por quatro semanas consecutivas. Para a região onde a pesquisa foi desenvolvida, as estações do ano tiveram pouca influência no desenvolvimento do processo de compostagem. A Figura 03 apresenta o gráfico de temperatura para a Leira 01 .
Figura 03: Gráfico do acompanhamento de temperatura ambiente e da temperatura da Leira 01 durante 90 dias.

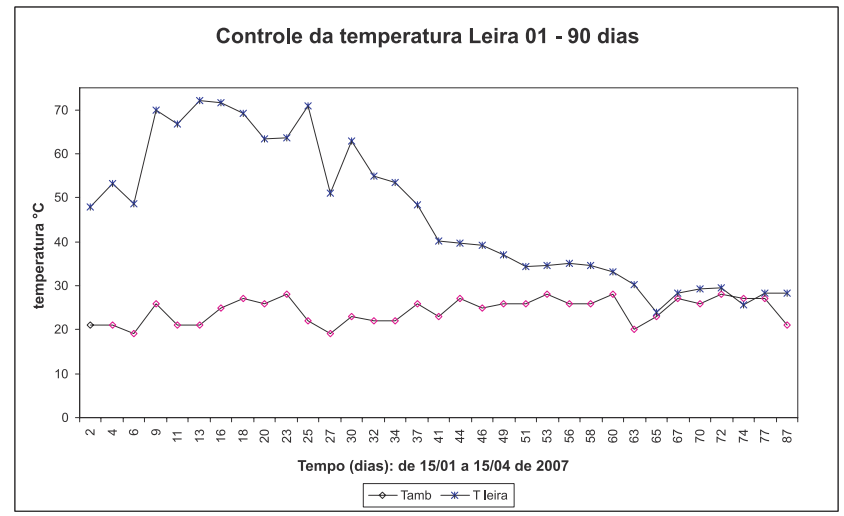

Observa-se que a temperatura da leira foi maior no início da compostagem, caracterizando a fase termófila. É interessante notar que após a trituração da leira (linha pontilhada em vermelho) ocorreu um aumento da sua temperatura, uma vez que a homogeneização do tamanho das partículas permitiu maior taxa de decomposição dos materiais. $\mathrm{O}$ acompanhamento da temperatura se deu para as 56 leiras montadas durante o experimento, sendo que todas elas tiveram comportamento semelhante a Leira 01.Com relação à quantidade de água recebida em cada leira, a média foi de 203 litros por leira. As leiras que mais receberam água, acima de 300 litros, foram aquelas montadas durante o inverno, posto a umidade relativa do ar ser mais baixa nessa época. Por outro lado, as leiras iniciadas no verão tiveram a menor quantidade de água, cerca de 125 litros, cada uma. Ao final do processo de compostagem, a umidade média do composto pronto foi de $30 \%$ e $\mathrm{pH}$ de 8,5. Para todas as amostras, a natureza física do composto foi classificada como farelado. A partir dos resultados infere-se que o composto produzido no Pátio enquadra-se nos limites estabelecidos pela Instrução Normativa $n^{\circ}$ 23 (MAPA, 2005), na qual a umidade deve ser, no máximo, igual a 50\% e pH, no mínimo, 6,5. A Tabela 5 apresenta os valores obtidos do teor de matéria orgânica, carbono, nitrogênio, capacidade de troca catiônica e macro e micronutrientes do composto produzido no Pátio, comparando, quando possível, com a legislação existente (IN 23/2005).

Tabela 5. Resultados da análise do composto e valores limites estabelecidos pela IN $23 / 2005$.

\begin{tabular}{|c|c|c|}
\hline Parâmetro & $\begin{array}{l}\text { Composto } \\
\text { (valor médio) }\end{array}$ & IN $23 / 2005$ \\
\hline CTC (mmolkg) & 310.0 & $\begin{array}{ll}-- \\
--\end{array}$ \\
\hline $\begin{array}{l}\text { Matéria orgânica } \\
(\%)\end{array}$ & 37.0 & mín $40 \%$ \\
\hline $\begin{array}{l}\text { Carbono orgânico } \\
(\%)\end{array}$ & 20.5 & mín $15 \%$ \\
\hline Nitrogênio (\%) & 2.1 & mín 1 \\
\hline Relação C/N & 10.2 & $\max 18 / 1$ \\
\hline Relação CTC/C & 15.10 & mín $20 \%$ \\
\hline $\mathrm{Ca}(\mathrm{g} / \mathrm{kg})$ & 26.5 & --- \\
\hline $\mathrm{Mg}(\mathrm{g} / \mathrm{kg})$ & 2.2 & --- \\
\hline$P(g / k g)$ & 4.5 & --- \\
\hline $\mathrm{K}(\mathrm{g} / \mathrm{kg})$ & 11.0 & --- \\
\hline $\mathrm{S}(\mathrm{g} / \mathrm{kg})$ & 2.8 & --- \\
\hline $\mathrm{Cu}(\mathrm{mg} / \mathrm{kg})$ & 22.7 & --- \\
\hline $\mathrm{Fe}(\mathrm{g} / \mathrm{kg})$ & 28.21 & --- \\
\hline $\mathrm{Mn}(\mathrm{mg} / \mathrm{kg})$ & 175.4 & --- \\
\hline $\mathrm{Zn}(\mathrm{mg} / \mathrm{kg})$ & 75.1 & --- \\
\hline
\end{tabular}

Fonte: Massukado (2008)

A Tabela 06 apresenta os teores de metais pesados e organismos patogêncios contidos no composto e compara com a legislação vigente (IN 27/2006). 


\section{artigos técnicos}

Tabela 06: Teores de metais pesados e organismos patogênicos contidos no composto e comparção com a legislação vigente (IN 27/2006).

\begin{tabular}{|c|c|c|c|c|c|c|c|c|c|c|}
\hline \multirow[b]{2}{*}{ Substância (mg/kg) } & \multicolumn{9}{|c|}{ LEIRAS } & \multirow{2}{*}{$\begin{array}{l}\text { IN } \\
27 / 2006\end{array}$} \\
\hline & 1 & 2 & 3 & 11 & 12 & 27 & 28 & 29 & 30 & \\
\hline $\mathrm{Cd}$ & $<1,0$ & $<1,0$ & $<1,0$ & $<0,5$ & $<0,5$ & $<0,5$ & $<0,5$ & $<0,5$ & $<0,5$ & \\
\hline $\mathrm{Pb}$ & $<1,0$ & $<1,0$ & $<1,0$ & 23 & 7,8 & 1,5 & $<0,5$ & 1,3 & 2,9 & 150 \\
\hline $\mathrm{Cr}$ & 13,7 & 16,2 & 14,1 & 23,3 & 24,3 & 17,8 & $<0,5$ & 17,4 & 31,1 & 200 \\
\hline $\mathrm{Ni}$ & $<1,0$ & $<1,0$ & $<1,0$ & 1,6 & 1,4 & 1,9 & $<0,5$ & 0,8 & 2,1 & 70 \\
\hline As & $\mathrm{NA}$ & NA & $\mathrm{NA}$ & $<0,5$ & $<0,5$ & $<0,5$ & $<0,5$ & $<0,5$ & $<0,5$ & 20 \\
\hline $\mathrm{Hg}$ & NA & NA & NA & $<0,5$ & $<0,5$ & $<0,5$ & $<0,5$ & $<0,5$ & $<0,5$ & 1 \\
\hline $\mathrm{Se}$ & NA & NA & NA & $<0,5$ & 58,1 & $<0,5$ & $<0,5$ & $<0,5$ & $<0,5$ & 80 \\
\hline \multicolumn{11}{|c|}{ Organismos patogênicos } \\
\hline $\begin{array}{l}\text { coliformes fecais } \\
\text { (NMP/g ST) } \\
\text { coliformes totais }\end{array}$ & $<2.2$ & $<2.2$ & $<2.2$ & $<2.2$ & $<2.2$ & $<2.2$ & $<2.2$ & $<2.2$ & $<2.2$ & \\
\hline (NMP/g ST) & 240 & 600 & 89000 & 85 & 158 & 2 & 3 & 345 & 28 & $\begin{array}{l}\text { Ausência } \\
\text { em } 10 \mathrm{~g} \mathrm{de}\end{array}$ \\
\hline $\begin{array}{l}\text { Salmonella (NMP/ } 4 \mathrm{~g} \text { ) } \\
\text { coliformes } \\
\text { termotolerantes }\end{array}$ & $<2.2$ & ausente & 14 & 50 & 90 & $<2.2$ & $<2.2$ & $<2.2$ & $<2.2$ & MS \\
\hline $\begin{array}{l}\text { (NMP/g de MS) } \\
\text { Ovos viáveis de } \\
\text { helmintos (n }{ }^{\circ} \text { ovos } / 4 \mathrm{~g}\end{array}$ & NA & NA & NA & NA & NA & 7 & 15 & 136 & 8 & 1000 \\
\hline ST) & NA & NA & NA & NA & NA & 0 & 0 & 0 & $\mathrm{NA}$ & 1 \\
\hline
\end{tabular}

Os resultados indicaram que o composto atende à maioria dos limites estabelecidos pela legislação brasileira, principalmente, com relação à concentração de metais pesados $(\mathrm{Cd}<0.5, \mathrm{~Pb}=1.3, \mathrm{Cr}=17.4$, As $<0.5, \mathrm{Hg}<0.5, \mathrm{Se}<0.5$ e $\mathrm{Ni}=0.8, \mathrm{em} \mathrm{mg} / \mathrm{kg}$ ) e presença de organismos patogênicos. A partir da Tabela 06 pode-se afirmar que a não presença de ovos de helmintos no composto pode ser decorrente da compostagem ter sido realizada somente com os resíduos sólidos urbanos, não havendo adição de esgoto doméstico. Com relação aos coliformes termotolerantes, todas as amostras se enquadram dentro do limite estabelecido pela $\mathrm{IN} \mathrm{n}^{\circ} 27 / 2006$.

\section{Ensaio Ecotoxicológico}

A Tabela 07 apresenta algumas características do TAS, utilizado como controle, e da substância-teste, ou seja, o composto orgânico.

Tabela 07: Características do TAS e da substância-teste utilizada no ensaio de toxicidade aguda.

\begin{tabular}{lll}
\hline Variável & $\begin{array}{l}\text { Comp } \\
\text { osto }\end{array}$ & TAS \\
\hline Umidade & 17,78 & 5,79 \\
pH & 8,29 & 6,19 \\
CRA (\%) & 83,83 & 61,08 \\
Condutividade elétrica $(\mathrm{mS} / \mathrm{cm})$ & 7,48 & 1,76 \\
CTC (mmol/kg) & 318 & \\
Matéria orgânica (\%) & 35,53 \\
Carbono orgânico (\%) & 19,74 \\
Nitrogênio $(\%)$ & 2,21 \\
Relação C/N & 8,91 \\
K solúvel $(\mathrm{g} / \mathrm{kg})$ & 9,67 \\
Na solúvel $(\mathrm{g} / \mathrm{kg})$ & 6,61 \\
N-NH $(\mathrm{mg} / \mathrm{kg})$ & 456,67 \\
Cádmio $(\mathrm{mg} / \mathrm{kg})$ & $<0,5$ \\
Chumbo $(\mathrm{mg} / \mathrm{kg})$ & 1,3 \\
Cromo $(\mathrm{mg} / \mathrm{kg})$ & 17,4 \\
Arsênio $(\mathrm{mg} / \mathrm{kg})$ & $<0,5$ \\
Mercúrio $(\mathrm{mg} / \mathrm{kg})$ & $<0,5$ \\
Níquel $(\mathrm{mg} / \mathrm{kg})$ & 0,8 \\
Coliformes fecais (NMP/g) & $<2,2$ \\
Coliformes totais (NMP/g) & 345 \\
Coliformes termotolerantes (NMP/g & 136 \\
MS seca) & \\
Salmonella (NMP/4g) & $<2,2$ \\
\hline Fonte: Massukado (2008) &
\end{tabular}

Os resultados obtidos nos ensaios de toxicidade aguda para o composto proveniente do Pátio de Compostagem são apresentados na Tabela 08.
Tabela 08: Resultados do Teste de Toxicidade Aguda do composto de lixo produzido no Pátio de Compostagem, São Carlos, 2008.

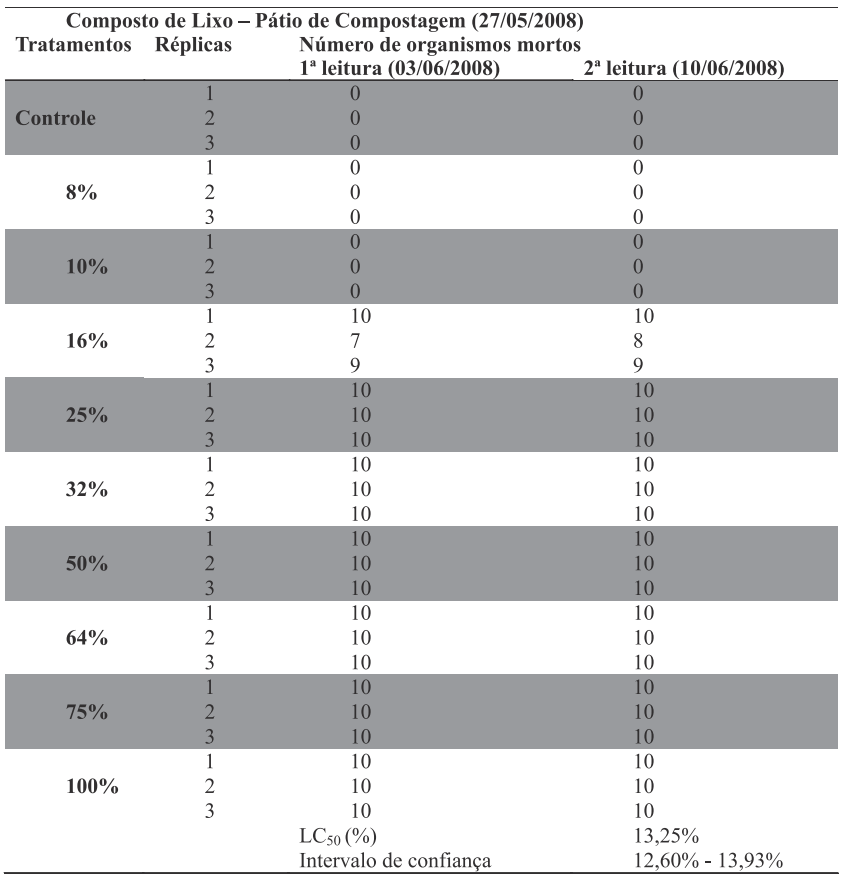

Fonte: Massukado (2008)

Nesse teste, as minhocas ficaram extremamente agitadas ao serem introduzidas no recipiente que continha $100 \%$ de composto de lixo do Pátio, resultando na morte de todas em 15 minutos. Nos recipientes com concentrações entre $25 \%$ e $75 \%$, logo na primeira leitura $(7$ dias), as minhocas já estavam mortas e em estado de decomposição, verificado pela presença de fungos.A análise dos resultados foi realizada com o auxílio do programa Trimmed Spearman-Kärber, o qual estimou a $\mathrm{CL}_{50}$ (concentração capaz de causar efeito letal em 50\% dos organismos) equivalente a 13,25 $\pm 5 \%$ (concentração) de composto de lixo, com intervalos de confiança de $95 \%$. Analisando este resultado e transformando-o para valores da dose recomendada para aplicação agrícola, conclui-se que a dose de $120 \mathrm{t} / \mathrm{ha}(8 \%)$ está abaixo da $\mathrm{CL}_{50}$. A situação torna-se preocupante quando a $\mathrm{CL}_{50}$ é analisada sob o ponto de vista da conversão pela área, geralmente mais comum, na qual a dose recomendada de 120 t/ha (32\%) deveria ser reduzida para, no máximo, $50 \mathrm{t} / \mathrm{ha}(13,25 \%)$. Alvarenga et al. (2007) realizaram estudo sobre as características químicas e ecotoxicológicas de composto proveniente de três diferentes tipos de resíduos orgânicos biodegradáveis - lodo de esgoto, composto de lixo proveniente da coleta misturada e composto de resíduos de poda - considerando o seu uso na agricultura. As concentrações testadas foram $100 \%, 75 \%, 50 \%$ e $25 \%$. Os resultados obtidos mostraram que o lodo de esgoto apresentou índice elevado de $\mathrm{Zn}$ e significativa mortalidade para o teste agudo com minhocas $\left(\mathrm{CL}_{50}\right.$ $=59,1 \%)$. O composto de lixo apresentou os maiores efeitos tóxicos no teste agudo $\left(\mathrm{CL}_{50}=21,4 \%\right)$ sendo que a concentração de metais pesados $(\mathrm{Cd}=4,3 ; \mathrm{Cr}=56 ; \mathrm{Cu}=357 ; \mathrm{Ni}=56 ; \mathrm{Pb}=269$ e $\mathrm{Zn}=583$, em mg/ $\mathrm{kg})$ e a alta condutividade elétrica $(5,69 \mathrm{mS} / \mathrm{cm})$ foram consideradas as responsáveis pela maior toxicidade do composto de lixo. Para o composto de resíduos de poda não foi calculada concentração letal, pois a mortalidade não foi superior a $50 \%$ em qualquer dos tratamentos. Klar (1988) afirma que as culturas respondem diferentemente aos valores de condutividade elétrica, sendo que os efeitos da salinidade para as plantas são negligenciáveis entre 0 e $2 \mathrm{mS} / \mathrm{cm}$; de 2 a $4 \mathrm{~ms} /$ $\mathrm{cm}$ pode ocorrer restrição do desenvolvimento de algumas culturas; de 4 a $8 \mathrm{mS} / \mathrm{cm}$ muitas culturas diminuem a produção e de 8 a $16 \mathrm{mS} /$ $\mathrm{cm}$ só algumas plantas produzem satisfatoriamente. Com relação ao uso do composto de lixo no solo, Silva et al. (2002) recomendam a manutenção da condutividade abaixo de $4 \mathrm{dS} / \mathrm{m}(4 \mathrm{mS} / \mathrm{cm})$, enquanto 
Abreu et al. (2000) são mais restritivos, considerando o valor de $2 \mathrm{mS} /$ cm como crítico.

Para investigar melhor a relação entre condutividade elétrica e toxicidade realizou-se a determinação desse parâmetro ao final do teste para os tratamentos que apresentaram sobreviventes (Tabela 09).

Tabela 09: Determinação da condutividade elétrica $(\mu S / \mathrm{cm})$ dos tratamentos que tiveram sobreviventes. Extrato solo-água 1:5 (m:v)

\begin{tabular}{cc}
\hline Tratamento & $\begin{array}{c}\text { Condutividade elétrica } \\
(\boldsymbol{\mu S} / \mathbf{c m})\end{array}$ \\
\hline $8 \%$ & 1081 \\
$10 \%$ & 1278 \\
$16 \%$ & 1901 \\
\hline
\end{tabular}

A partir da Tabela 09 , pode-se observar que a concentração de $16 \%$ do composto do Pátio de Compostagem, no qual ainda houve sobreviventes, apresentou condutividade elétrica próxima ao valor recomendado por Abreu et al (2000). Portanto, infere-se que existe uma relação entre a toxicidade do composto e a sua condutividade elétrica.Ao final dos ensaios, realizou-se a pesagem das minhocas para verificar o ganho ou perda de biomassa com relação ao início do teste. Utilizou-se o método estatístico ANOVA - teste de Dunnet, para uma variável, para testar a hipótese de que o peso das minhocas não é alterado pela introdução

\section{CONCLUSÃO}

Apesar do composto produzido no Pátio de Compostagem se enquadrar nos padrões de qualidade estabelecidos pela legislação brasileira, os resultados do ensaio agudo realizado com minhocas da espécie Eisenia andrei indicaram toxicidade do composto para essa biota. A partir desse teste, infere-se que somente a avaliação dos parâmetros físicos, químicos e microbiológicos do composto de lixo não são suficientes para assegurar a sua aplicação segura no solo, pois seu uso indiscriminado poderá provocar alterações na biota terrestre.

A alta condutividade elétrica $(\mathrm{CE}=7,45 \mathrm{mS} / \mathrm{cm})$ do composto proveniente do Pátio de Compostagem pode ter contribuído pela toxicidade do composto para a minhoca, uma vez que os teores de metais pesados estiveram muito abaixo dos limites estabelecidos pela legislação. Há que se ressaltar também a possibilidade do nitrogênio

\section{AGRADECIMENTOS}

Os autores agradecem ao Conselho Nacional de Desenvolvimento Científico e Tecnológico (CNPq), pela bolsa concedida, e à Fundação de Amparo à Pesquisa do Estado de São Paulo (FAPESP), por financiar esta pesquisa. Agradecem, também, aos parceiros do projeto - Prefeitura Municipal de São Carlos, Escola Estadual Bento da Silva César, Escola de Engenharia de São Carlos (EESC/USP), Centro de Divulgação Científica e Cultural (CDCC/ USP) e Associação para Proteção Ambiental de São Carlos (APASC).

\section{REFERÊNCIAS}

1. ABREU JUNIOR., C. H.; MURAOKA, T. LAVORANTE A. F. \& ALVAREZ, V. F. C. Condutividade elétrica, reação do solo e acidez potencial em solos adubados com composto de lixo. Revista Brasileira de Ciências do Solo, Viçosa, v. 24, p. 635-647, 2000.

2. ALVARENGA, P.; PALMA, P.; GONCALVES,A.P.; FERNANDES, R. M.; CUNHA-QUEDA, A. C.; DUARTE, E.; VALLINI, G. Evaluation of chemical and ecotoxicological characteristics of biodegradable organic residues for application to agricultural land. Environmental International, v.33, p.505-513, 2007.

3. ASSOCIAÇÃO BRASILEIRA DE NORMAS TÉCNICAS (ABNT) NBR 13.591 : Compostagem: Terminologia. Rio de Janeiro, 1996. do composto de lixo nos tratamentos do experimento. Como esse teste requer no mínimo três réplicas (pesos) para cada tratamento, os de 16\% a $100 \%$ do Pátio de Compostagem não puderam ser comparados com o controle. A Tabela 10 apresenta somente o peso inicial e final para os

\begin{tabular}{|c|c|c|c|}
\hline \multicolumn{4}{|c|}{ Peso médio minhocas (mg) } \\
\hline Tratamento & $\begin{array}{l}\text { Comp } \\
\text { início }\end{array}$ & Fim & variação \% \\
\hline Controle & 325.0 & 263.0 & -19 \\
\hline $8 \%$ & 331.7 & 408.0 & 23 \\
\hline $10 \%$ & 282.3 & 343.0 & 22 \\
\hline $16 \%$ & 270.5 & 155.0 & -43 \\
\hline
\end{tabular}

Tabela 10: Resultado do monitoramento dos pesos médios das minhocas, antes e após o ensaio de toxicidade aguda

tratamentos que não tiveram $100 \%$ de mortalidade.

Ao analisar esses dados (Tabela 10), observa-se que para o composto de lixo produzido no Pátio de Compostagem o ganho de peso da minhoca somente é verificado nos tratamentos onde não houve mortalidade $(8 \%$ e $10 \%$ ). Por outro lado, no tratamento com concentração de $16 \%$, onde somente 3 organismos sobreviveram, a perda de peso correspondeu a $43 \%$. No controle, houve perda de peso equivalente a $19 \%$, o que pode ser explicado pela menor disponibilidade de matéria orgânica para as minhocas. amoniacal $(456,67 \mathrm{mg} / \mathrm{kg})$ ter sido, juntamente com a condutividade elétrica, tóxico às minhocas.

Com relação aos parâmetros de qualidade do composto estabelecidos pelas leis brasileiras, infere-se que a iniciativa do Ministério da Agricultura, Pecuária e Abastecimento em regulamentar o uso do fertilizante orgânico é de suma importância para incentivar o desenvolvimento de novas atividades relacionadas à compostagem dos resíduos sólidos urbanos.

Nesse contexto, as Universidades têm a responsabilidade de desenvolver novas pesquisas que forneçam subsídios para melhorar as regulamentações e critérios de qualidade do composto, visando uma aplicação segura na agricultura.

\section{Nut}

105

7. B

Intel

Mar

8. B

Apr

sim!

agri

da L

\section{D}

A re

10.

\section{Obo}

org

$11 . \mathrm{E}$
Cen

Eart
RM

\section{2.}

ecot

(Do
Bon

\section{3.}

usin

de
Uni

14.

STA
poll

toxi

\section{ASSOCIATION OF CITIES AND REGIONS FOR RECYCLING} AND SUSTAINABLE RESOURCE MANAGEMENT - ACR. Gestão dos resíduos domésticos biodegradáveis: Que perspectivas para as autoridades locais europeias? 2005. 126 p. Disponível em: http://www. lipor.pt/upload/Lipor/ficheiros/Guia\%20Gest\%C3\%A3o\%20de $\% 20$ res $\% \mathrm{C} 3 \% \mathrm{ADduos} \% 20 \mathrm{dom} \% \mathrm{C} 3 \% \mathrm{~A} 9$ sticos $\% 20$ biodegrad $\% \mathrm{C} 3 \% \mathrm{~A} 1$ veis_ vers $\%$ C3\%A3o\%20final.pdf. Acesso em 10 de maio de 2008.

6. AYUSO, M.; PASCUAL, J.A.; GARCIA, C.; HERNANDEZ, T. Evaluation of Urban Wastes for Agricultural Use. Soil Science Plant 
Nutrition. Japanese Society of Soil Science and Plant Nutrition, v. 42, p. 105-111, 1996.

7. BADE, O.; STREESE, J.; SEKITO, T.; STEGMANN, R. Integrated concept for decentralized waste water and biowaste treatment. In: International Waste Management and Landfill Symposium, 10, 2005, S. Margherita di Pula, Cagliari, Italy. Proceedings Sardinia... Cagliari, Italy.

8. BRASIL. Ministério de Agricultura, Pecuária e Abastecimento (MAPA). Aprova as definições e normas sobre as especificações e garantias, a tolerância, o registro, a embalagem e a rotulagem dos fertilizantes orgânicos simples, mistos, compostos, organominerais e biofertilizantes destinados à agricultura. Instrução Normativa ${ }^{\circ} 23,31$ de agosto de 2005. Diário Oficial da União, Brasília, DF, 8 set. 2005. Seção 1, Página 12.

9. DE BERTOLDI M, VALLINI G, PERAA. The biology of composting: A review. Waste Management \& Resource 1983; p. 153-176.

10. ENAYETULLAH, I; SINHA, A.H.M.M. (2001). Potentials Of Organic Waste Recycling Through Composting In Khulna City. In: Oborjana o Paribesh Newsletter. Disponível em: http://www.wasteconcern. org/ Acesso em : 15 de set 2006.

11.ENVIRONMENTAL CANADA (EC). Environmental Technology Centre. Biological Test Method: Tests for Toxicity of Contaminated Soil to Earthworms (Eisenia andrei, Eisenia fetida or Lumbricus terrestris). EPS 1/ RM/43. 2004 (with 2007 amendments). 184p. Ottawa, Ontário, Canadá.

12. GARCIA, M. Effects of pesticides on soil fauna: development of ecotoxicological test methods for tropical regions. 2004, $291 \mathrm{f}$. Tese (Doutorado) - Hohen Landwirtschaftlichen Fakultät, Universidade de Bonn.

13. GROSSI, M.G.L. Avaliação da qualidade dos produtos obtidos de usina de compostagem brasileira de lixo doméstico através da determinação de metais pesados e substâncias orgânicas tóxicas. Tese (Doutorado). 1993. Universidade de São Paulo, SP.

\section{INTERNATIONAL ORGANIZATION FOR} STANDARDIZATION (ISO). ISO 11262-1. Soil quality: effects of pollutants on earthworms (Eisenis fetida). Part 2: Determination of acute toxicity using soil substrate. Genebra: ISO. 1993.

15. KIEHL, E.J. Fertilizantes orgânicos. São Paulo: Agronômica Ceres. 492 p., 1985.

16. KIEHL, E.J. Manual de Compostagem. Piracicaba: Editora Ceres, 1998.

17. KIEHL, E.J. Manual de Compostagem: Maturação e Qualidade do Composto. $4^{\mathrm{a}}$ ed. Piracicaba, SP. 2004.

18. KLAR, A.E. A água no sistema solo-planta-atmosfera. 2.ed. São Paulo: Nobel, 1988. 408p.

19. LOPEZ-REAL, J.M. Agroindustrial waste composting and its agricultural significance. Proceedings of the Fertilizer Society, n. 293, p. 1-26, 1990.

20. MASSUKADO, L.M. Desenvolvimento do processo de compostagem em unidade descentralizada e proposta de software livre para o gerenciamento municipal dos resíduos sólidos domiciliares. 2008. 182 p. Tese (Doutorado) - Escola de Engenharia de São Carlos, Universidade de São Paulo, São Carlos, 2008.
21. MERILLOT, J.M. Perspectives and state of the art of composting in France. In: Marco de Bertoldi, Paolo Sequi, Bert Lemmes, Tiziano Papi. Science of Composting Part 2. $1^{\mathrm{a}}$ edição. England: Chapman \& Hall (Edit), 1996, p. $648-690$.

22. MINISTÉRIO DA AGRICULTURA, PECUÁRIA E ABASTECIMENTO. Instrução Normativa $\mathrm{n}^{\circ} 23$ - aprova as definições e normas sobre as especificações e as garantias, as tolerâncias, o registro, a embalagem e a rotulagem dos Fertilizantes Orgânicos simples, mistos, compostos, organominerais e biofertilizantes destinados à Agricultura. 2005. Disponível em: http://extranet.agricultura.gov.br/sislegis-consulta/ consultarLegislacao.do?operacao=visualizar\&id $=13025$. Acesso em: nov de 2006

23. Ministério de Agricultura, Pecuária e Abastecimento (MAPA). Dispõe sobre fertilizantes, corretivos, inoculantes e biofertilizantes, para serem produzidos, importados ou comercializados, deverão atender aos limites estabelecidos nos Anexos I, II, III, IV e V desta Instrução Normativa no que se refere às concentrações máximas admitidas para agentes fitotóxicos, patogênicos ao homem, animais e plantas, metais pesados tóxicos, pragas e ervas daninhas. Instrução Normativa $\mathrm{n}^{\circ} 27,05$ de junho de 2006. Diário Oficial da União, Brasília, DF, 9 jun. 2006. Seção 1 , Página 15.

24. MOREIRA, R.; SOUSA, J.P.; CANHOTO, C. Biological Testing of a digested sewage sludge and derived composts. Bioresource Technology (2008), doi: 10.1016/j.biortech.2008.02.046

25. ORGANISATION FOR ECONOMIC CO-OPERATION ANDDEVELOPMENT (OECD). Guideline for Testing of Chemicals n. 207: Earthworm Acute Toxicity Test. Paris: OECD. 1984.

26. Guideline for Testing of Chemicals n. 207: Earthworm Acute Toxicity Test. Paris: OECD. 1984.

27. OLIVEIRA, F. C. Disposição de "resíduo orgânico" e composto de lixo urbano num Latossolo Vermelho-Amarelo cultivado com cana-deaçucar. Piracicaba, Escola Superior de Agricultura "Luiz de Queiroz", 2000. 247p. (Tese de Doutorado).

28. OLIVEIRA, S.C. Estudos sobre métodos de compostagem de resíduos sólidos domésticos: grau de maturação e qualidade do composto. 2001. Tese (Doutorado em Química). Universidade Estadual Paulista, Campus Araraquara, SP.

29. RÖMBKE, J.; KNACKER, T. Standardisation of terrestrial ecotoxicological effect methods: an example of successful international co-operation. J. Soils \& Sediments, v. 3, n. 4, p. 237-238, 2003.

30. ROTHENBERGER, S.; ZURBRÜGG, C.; ENAYETULLAH, I.; SINHA,A.H.M.M. Descentralized Composting for cities of low-and Middle- Income Countries - A users'Manual. Publisher: Waste Concern; Bangladesh and Switzwerland. 2006. 109 p.

31. SAVAGE, G.M. The importance of waste characteristics and processing in the production of quality compost. In: Marco de Bertoldi, Paolo Sequi, Bert Lemmes, Tiziano Papi. Science of composting. Part 2. $1^{\text {a }}$ edition. England: Chapman \& Hall (edit), 1996. pp. 784-791.

32. SENESI N. Composted materials as organic fertilizers. The Science of the Total Environment. p. 521-542, 1989.

33. SILVA, F.C.; BERTON, R.S.; CHITOLINA, J.C; BALESTEIRO, S.D. Agropecuária: Uso agrícola do composto de lixo no Estado de São Paulo: recomendações técnicas. Campinas, MAPA, EMBRAPA, 2002. (Circular Técnica da Embrapa Informática Agropecuária) 